
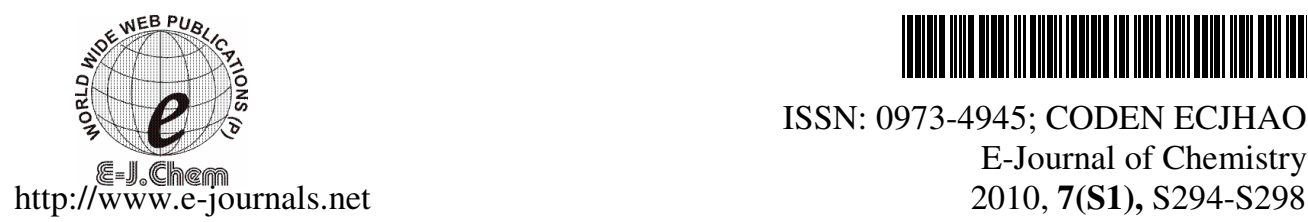

ISSN: 0973-4945; CODEN ECJHAO

E-Journal of Chemistry

2010, 7(S1), S294-S298

\title{
Synthesis and Characterization of (Z)-Furan-2-carbaldehyde Thiosemicarbazone at Low Temperature
}

\section{ALIREZA ABBASI, SHOKOOFEH GERANMAYEH, ALI NAGHI TAHERI ${ }^{\#}$, HASHEM SHAHROOSVAND $^{\S^{*}}$ and MOHSEN SHABANI ${ }^{\text {II }}$}

\author{
School of Chemistry \\ College of Science, University of Tehran, Tehran, Iran \\ ${ }^{\#}$ School of Chemistry, Shahrood University of Technology, I.R. Iran \\ ${ }^{\S}$ Department of Chemistry, Zanjan University, Zanjan, Iran

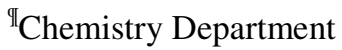 \\ Islamic Azad University, Varamin-Pishva Branch, Tehran, Iran \\ h.shahroosvand@gmail.com
}

Received 26 January 2010; Accepted 4 April 2010

\begin{abstract}
The compound, $\mathrm{C}_{6} \mathrm{H}_{7} \mathrm{~N}_{3} \mathrm{OS}$, has been prepared and characterized by condensation between thiosemicarbazide and furan-2-carbaldehyde and its structure was elucidated by x-ray analysis (at $150 \mathrm{~K}$ ), NMR and IR spectroscopy methods (at ambient temperature). It crystallizes in the monoclinic space group $P 2_{1} / c$ (No. 14), $\mathrm{a}=13.5099$ (3) $\AA, \mathrm{b}=5.67430(10) \AA$, $\mathrm{c}=23.4755(6) \AA, \beta=117.367(2)^{\circ}, \mathrm{V}=1598.20(7) \AA^{3}$ and $\mathrm{Z}=8$. The crystal structure was solved and refined to $R=0.0290$ with 2942 unique reflections. No significant $\pi-\pi$ interactions are found in the crystal structure. There are $\mathrm{C}-\mathrm{H} . . . \pi$ interactions and also different weak hydrogen bonds, stabilizing the three dimensional crystal structure.
\end{abstract}

Keywords: Thiosemicarbazide, Crystal structure, Synthesis, Furan.

\section{Introduction}

Thiosemicarbazones and their derivatives have been widely studied due to their various biological activities such as anticancer activities ${ }^{1,2}$. Tridentate N-N-S ligand system of thiosemicabazide seems to be a key for the antiviral, antibacterial and anticancer therapeutics ${ }^{3,4}$.

Transition metal complexes of thiosemicarbazone and their derivatives attracted considerable interest for their wide range of pharmacological properties such as antimicrobial $^{5,6}$, antiameobic ${ }^{7}$, antitumor ${ }^{8-11}$ and antiviral activity ${ }^{12,13}$. 
Therefore, many efforts were dedicated to investigate of the structure activity relationship of metal thiosemicarbazone complexes. Recently, thiosemicarbazone derivatives has been used for the determination of Cd(II) by using spectrophotometric method ${ }^{14}$.

However, heterocyclic thiosemicarbazones showed higher activity compared with aromatic thiosemicarbazones ${ }^{3}$. It has been shown that the trans thiosemicabazone are the most active isomer ${ }^{1}$. It seems likely that the oxygen atom of the furan ring plays an important role in determining the biological activity ${ }^{15}$. However, a much deeper study of the H-bonding and molecular interactions of these compounds would be needed for establishing the new activity aspects.

Therefore, a structural study in details for the title compound was of our interest. In this work, we first study the structure of the title compound at low temperature and compared with previous report at ambient temperature ${ }^{15}$.

\section{Experimental}

The crystallographic data were collected at low temperature by means of an x-calibur 3 equipped with a CCD area detector diffractometer, using graphite-monochromated Mo Ka radiation $(\lambda=0.71073 \AA)$ by $\omega$ scan mode. No intensity variations due to decomposition of the crystals were observed. Selected crystallographic and experimental details are summarized in Table 1.

Table 1. Crystal data and structure refinement for $\mathrm{C}_{6} \mathrm{H}_{7} \mathrm{~N}_{3} \mathrm{OS}$ at $150 \mathrm{~K}$

\begin{tabular}{|c|c|}
\hline Molecular formula & $\mathrm{C}_{6} \mathrm{H}_{7} \mathrm{~N}_{3} \mathrm{OS}$ \\
\hline Molecular weight & 169.22 \\
\hline Temperature, $\mathrm{K}$ & $150(2)$ \\
\hline Radiation $\lambda$ & 0.71073 \\
\hline Crystal system & Monoclinic \\
\hline Space group & $\mathrm{P} 2_{1} / \mathrm{c}$ \\
\hline $\mathrm{a} / \mathrm{A}$ & $13.5099(3)$ \\
\hline $\mathrm{b} / \AA ̊$ & $5.67430(10)$ \\
\hline c/ $\AA$ & $23.4755(6)$ \\
\hline$\beta\left({ }^{\circ}\right)$ & $117.367(2)$ \\
\hline $\mathrm{V} / \AA^{3}$ & $1598.20(7)$ \\
\hline $\mathrm{Z}$ & 8 \\
\hline $\mathrm{D}_{\text {calc }} \mathrm{g} \mathrm{cm}^{-3}$ & 1.407 \\
\hline Crystal size, $\mathrm{mm}$ & $0.17 \times 0.13 \times 0.12$ \\
\hline Crystal colour & Yellow \\
\hline Absorption coefficient, $\mathrm{cm}^{-1}$ & 0.349 \\
\hline $\mathrm{F}(000)$ & 704 \\
\hline Reflections collected/unique & $6484 / 2942$ \\
\hline Range/indices & $-16 \leq \mathrm{h} \geq 16,-6 \leq \mathrm{k} \geq 6,-28 \leq 1 \geq 22$ \\
\hline$\theta \operatorname{limit}\left({ }^{\circ}\right)$ & $3.90-25.50$ \\
\hline No. of observed data, $\mathrm{I}>2 \sigma(\mathrm{I})$ & 2290 \\
\hline No. of parameters & 199 \\
\hline No. of restraints & 0 \\
\hline Goodness of fit on $\mathrm{F}^{2}$ & 0.931 \\
\hline $\mathrm{R}_{1}, \mathrm{wR}_{2}[\mathrm{I} \geq 2 \sigma(\mathrm{I})]^{\mathrm{a}}$ & $0.0290,0.0621$ \\
\hline $\mathrm{R}_{1}, \mathrm{wR}_{2}$ (all data) & $0.0424,0.0646$ \\
\hline Largest diff. peak and hole & $0.194,-0.127$ \\
\hline
\end{tabular}


CrysAlis program packages were used for indexing and integrating the single crystal reflections ${ }^{16}$. Absorption corrections were performed with the program $\mathrm{x}-\mathrm{RED}$ and $\mathrm{x}$-SHAPE ${ }^{17}$. In $\mathrm{x}$-shape symmetry equivalent reflections were used to optimize the crystal shape and size. The structure was solved by direct methods using SHELXS-97 and refined using full-matrix least-squares method on $F^{2}$, SHELXL-9 $7^{18}$. Molecular graphics were drawn by Diamond and Mercury programs ${ }^{19}$ and PLATON ${ }^{20}$ software was used to prepare materials for publication. All non-hydrogen atoms were refined anisotropically. Aromatic and methine $\mathrm{H}$ atoms were placed in calculated positions $(\mathrm{C}-\mathrm{H}=0.93 \AA)$ and constrained to ride on their parent atoms, with $U_{\text {iso }}(\mathrm{H})=1.2 U_{\text {eq }}(\mathrm{C})$. The rest of $\mathrm{H}$ atoms were located in difference electron density maps and their coordinates were refined freely with $U_{\text {iso }}(\mathrm{H})=1.2 U_{\text {eq }}(\mathrm{N})$.

$\mathrm{NMR}$ experiments were recorded at room temperature in $\mathrm{CDCl}_{3}$ on a Bruker AV-500 spectrometer using an internal deuterated solvent lock. IR spectra were recorded as $\mathrm{KBr}$ disks on a Shimatzu IR instrument. Elemental analyses were performed using a Heraeus $\mathrm{CHN}-\mathrm{O}$ rapid analyzer. Al reagents and solvents used in this study were purchased from Merck \& Aldrich.

(Z)-Furan-2-carbaldehyde thiosemicarbazone (I) was prepared according to the modified procedure described in the literature ${ }^{1}$. A solution of thiosemicarbazide $(0.91 \mathrm{~g}, 10$ mmol) in $40 \mathrm{~mL}$ of dry methanol was prepared with stirring and warming (about $40{ }^{\circ} \mathrm{C}$ ) during $1 \mathrm{~h}$. To the warm thiosemicarbazide solution, furan-2-carbaldehyde $(0.96 \mathrm{~g}, 10$ $\mathrm{mmol}$ ) in $10 \mathrm{~mL}$ of dry methanol was added following by a $12 \mathrm{~h}$ reflux (Figure 1). The mixture was then slowly cooled down to room temperature until the yellowish needle crystals suitable for crystallography were obtained. Yield: $1.31 \mathrm{~g}(77 \%)$. Anal. Calcd for $\mathrm{C}_{6} \mathrm{H}_{7} \mathrm{~N}_{3} \mathrm{OS}$ : C, 42.60; H, 4.16; N, 24.83; S, 18.94. Found: C, 42.41; H, 4.12; N, 24.76; S, $18.88 \%$. IR (KBr) $\quad\left(v_{\max } / \mathrm{cm}^{-1}\right): 3135(\mathrm{~s}), 2887(\mathrm{~m}), 1620(\mathrm{~s}), 1612(\mathrm{~s}), 1575(\mathrm{~s}), 774(\mathrm{~m})$. ${ }^{1} \mathrm{H}$ NMR ( $\delta$, DMSO-d $\left.\mathrm{d}_{6}, 25{ }^{\circ} \mathrm{C}, \mathrm{ppm}\right): 11.40(\mathrm{~s}, 1 \mathrm{H}, \mathrm{NHCS}), 8.41(\mathrm{~s}, 1 \mathrm{H}, \mathrm{CH}=\mathrm{N}), 8.10$ and 7.92 (2br s, $1 \mathrm{H}$ each, $\left.\mathrm{NH}_{2}\right), 6.11-7.54$ (m, 3H, aromatic); ${ }^{13} \mathrm{C}$ NMR $\left(\delta\right.$, DMSO-d $6,25{ }^{\circ} \mathrm{C}$, ppm): $177.60(\mathrm{C}=\mathrm{S}), 139.54(\mathrm{CH}=\mathrm{N}), 148.68,142.8,108.5,109.01$ (C-aromatic).

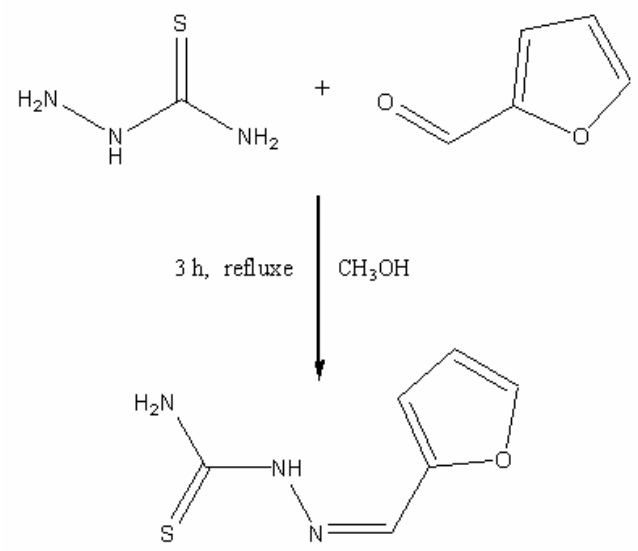

Figure 1. Synthetic and chemical structure of the compound (I)

\section{Results and Discussion}

(Z)-Furan-2-carbaldehyde thiosemicarbazone (I) was prepared by condensation between thiosemicarbazide and furan-2-carbaldehyde (Figure 1). The molecular structure of $\mathbf{I}$ and the atom-numbering scheme are shown in Figure 2. In the asymmetric unit there are two independent 
molecules with similar bond distances and angles (Table 2), however, in one molecule the furan ring is almost coplanar with the least-squares plane defined by thiosemicarbazide by dihedral angle of $7.2^{\circ}$, while in the other molecule the furan is twisted to the corresponding thiosemicarbazide by $23.2^{\circ}$.

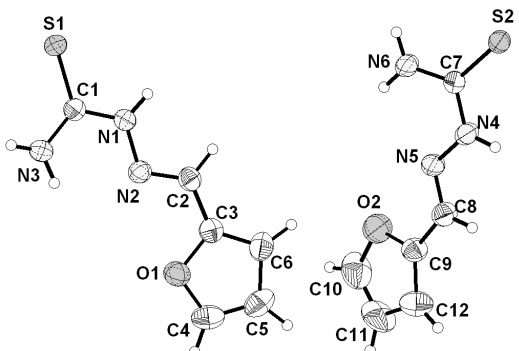

Figure 2. ORTEP structure of the compound (I), showing 50\% probability ellipsoids ( $\mathrm{H}$ atoms are shown as circles of arbitrary radii.)

Table 2. Selected bond distances $(\AA)$ for the compound (I)

\begin{tabular}{ccccccc}
\hline D & H & A & D-H & H..A & D..A & D-H..A \\
\hline N1 & H1A & S1 & 0.86 & $2.695(3)$ & $3.479(3)$ & 152.09 \\
N4 & H4A & S1 & 0.86 & $2.497(2)$ & $3.335(3)$ & 164.84 \\
N3 & H7 & S2 & 0.84 & $2.588(1)$ & $3.426(2)$ & 174.35 \\
N6 & H13 & S2 & 0.87 & $2.465(1)$ & $3.329(1)$ & 171.26 \\
C10 & H10 & O1 & 0.93 & $2.709(1)$ & $3.497(2)$ & 143.06 \\
\hline
\end{tabular}

There are $\mathrm{C}-\mathrm{H} . . . \pi$ interactions (e.g. $\mathrm{C} 4-\mathrm{H} 3{ }^{\mathrm{i}} \ldots \mathrm{Cg} 3=2.76 \AA$ being the ring O1/C $3 / \mathrm{C} 6 / \mathrm{C} 5 / \mathrm{C} 4$ with $\mathrm{i}=-\mathrm{x}, 1 / 2+\mathrm{y}, 1 / 2-\mathrm{z}$ ) and also different weak hydrogen bonds (Table 2), stabilizing the three dimensional crystal structure. No significant $\pi$ - $\pi$ interactions are found in the crystal structure.

The C1-S1 and C7-S2 bond lengths of 1.688(2) and 1.690(1) $\AA$, respectively are consistent with $\mathrm{C}=\mathrm{S}$ double bond. Likewise, the $\mathrm{N} 2-\mathrm{C} 2$ and N5-C8 bond distances with $1.277(2)$ and 1.271(2) $\AA$, respectively, are in accordance with $\mathrm{N}=\mathrm{C}$ double bond character, as well (Table 3). The bond angles for both furan rings are within normal ranges. As expected, the obtained data at low temperature have lower atomic movements, indicating lower thermal parameters in comparison to the data at room temperature ${ }^{13}$. Furthermore, in the current study we focused mainly structural and packing aspects, which was not specifically devoted before.

Table 3. Selected bond distances $(\AA)$ for the title compound.

\begin{tabular}{cccc}
\hline S1-C1 & $1.6880(14)$ & N4-C7 & $1.3407(18)$ \\
\hline S2-C7 & $1.6902(14)$ & N4-N5 & $1.3726(16)$ \\
O1-C3 & $1.3722(17)$ & N5-C8 & $1.2707(19)$ \\
O1-C4 & $1.3619(19)$ & N6-C7 & $1.3123(17)$ \\
O2-C9 & $1.3630(19)$ & C2-C3 & $1.434(2)$ \\
O2-C10 & $1.362(2)$ & C3-C6 & $1.346(2)$ \\
N1-C1 & $1.3432(17)$ & C4-C5 & $1.335(2)$ \\
N1-N2 & $1.3719(16)$ & C5-C6 & $1.417(2)$ \\
N2-C2 & $1.2768(17)$ & C9-C12 & $1.346(2)$ \\
N3-C1 & $1.3249(17)$ & C10-C11 & $1.319(3)$ \\
C11-C12 & $1.410(3)$ & C8-C9 & $1.434(2)$ \\
\hline
\end{tabular}


To gain new insight to the subject of supramolecular thiosemicarbazone arrays and to further extend the behavior antibacterial of metal complexes of the above amine substituted thiosemicarbazones with different metals, Further works on thiosemicarbazone derivates is in progress in our labratorary. Moreover, to fundamentally understand how differences in the structures of thiosemicarbazone derivates affect the intermolecular modes of thiosemicarbazone self-assembly, a more detailed available investigation of x-ray crystallography properties and supramolecualr arrayes directed by noncovalent bonding such as hydrogen bonding or $\pi$ - $\pi$ interactions needs to be done.

\section{Supporting information materials}

Crystallographic data for the title compound has been deposited to the Cambridge Crystallographic Data Centre (CCDC No. 704543). Copies of available materials can be obtained free of charge on application to the Director, CCDC, 12 Union Road, Cambridge CB2 IEZ, UK (fax: (44)01223 336033); e-mail: deposit@ccdc.ac.uk).

\section{Acknowledgments}

This work was supported by grants from the University of Tehran and the Swedish Research Council.

\section{References}

1. Dilovic I, Rubcic M, Vrdoljak V, Pavelic S K, Kralj M, Piantanidab I and Cindrica M, Bioorg Med Chem., 2008, 16, 5189.

2. Zhang H, Thomas R, Oupicky D and Peng F, J Biol Inorg Chem., 2008, 13(1), 47-55.

3. Hu W X, Zhou W, Xia CN and Wen X, Bioorg Med Chem Lett., 2006, 16(8), 2213-2218.

4. Rana A K, Parekh N R, Dabhi H R and Nadkarni S S, E-J Chem., 2009, 6(3), 747.

5. Kolocouris A, Dimas K, Pannecouque C, Andrei G, Snoeckc R and De Clercq E, Bioorg Med Chem Lett., 2002, 12, 723-727.

6. Logu A D, Saddi M, Onnis V, Sanna C, Congiu C, Borgna R and Cocco M T, Int J Antimicrob Agents, 2005, 26(1), 28-32.

7. Maurya M R, Shailendra S K, Azam A, Zhang W and Rehder D, Eur J Inorg Chem., 2003, 24, 43.

8. Ainscough E W, Brodie A M, Denny W A, Finlay G J and Ranford J D, J Inorg Biochem., 1998, 70(3-4), 175-185.

9. Chin L S, Murray S F, Harter D H, Doherty P F and Singh S K, J Biomed Sci., 1999, 6(3), 213-218.

10. Sau D K, Butcher R J, Chaudhuri S and Saha N, Mol Cell Biochem., 2003, 253(1-2), 21-29.

11. Bal T, Atasever B, Solakoglu Z, Erdem-Kuruca S and Ulkuseven B, Eur J Med Chem., 2007, 42(2), 161-167.

12. Varadinova T, Demertzi D K, Rupelieva M, Demertzis M and Genova P, Acta Virology, 2001, 45(2), 87-94.

13. Mishra V, Pandeya S N, Pannecouque C, Witvrouw M and De Clercq E, Arch Pharm., 2002, 335(5), 183-186.

14. Parikh K S, Patel R M, Patel K N, E-J Chem., 2009, 6(S1), S496-S500.

15. Bathia S C, Guatam P, Chatrath A K and Jain P C, Indian J Chem., 1993, 32, 1237.

16. CrysAlis CCD and CrysAlis RED. Version 1.171.29.2, Oxford Diffraction Ltd, Abingdon, Oxfordshire, England, 2003.

17. X-SHAPE version $1.02 \&$ X-RED version 1.09 , Stoe \& Cie GmbH, Darmstadt, Germany, 1997.

18. Sheldrick G M, SHELXS97 and SHELXL97. University of Götingen, Germany, 1997.

19. Brandenburg K, DIAMOND. Version 2.1e. Crystal Impact GbR, Bonn, Germany, 2001.

20. Spek A L, J Appl Cryst., 2003, 36, 7-13. 


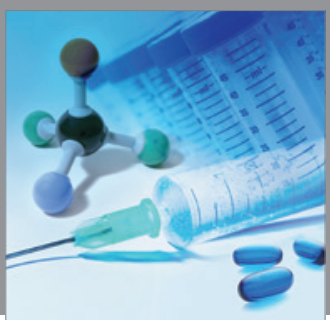

International Journal of

Medicinal Chemistry

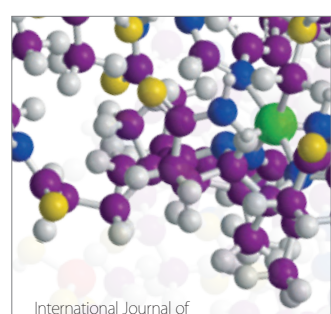

Carbohydrate Chemistry

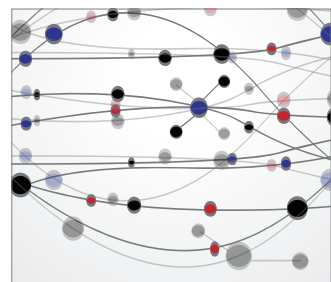

The Scientific World Journal
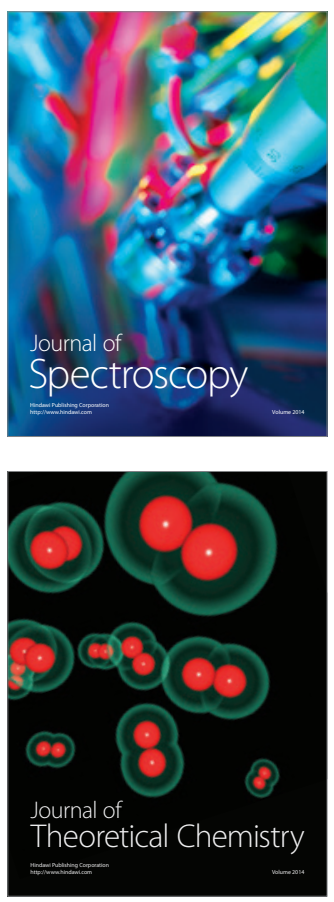
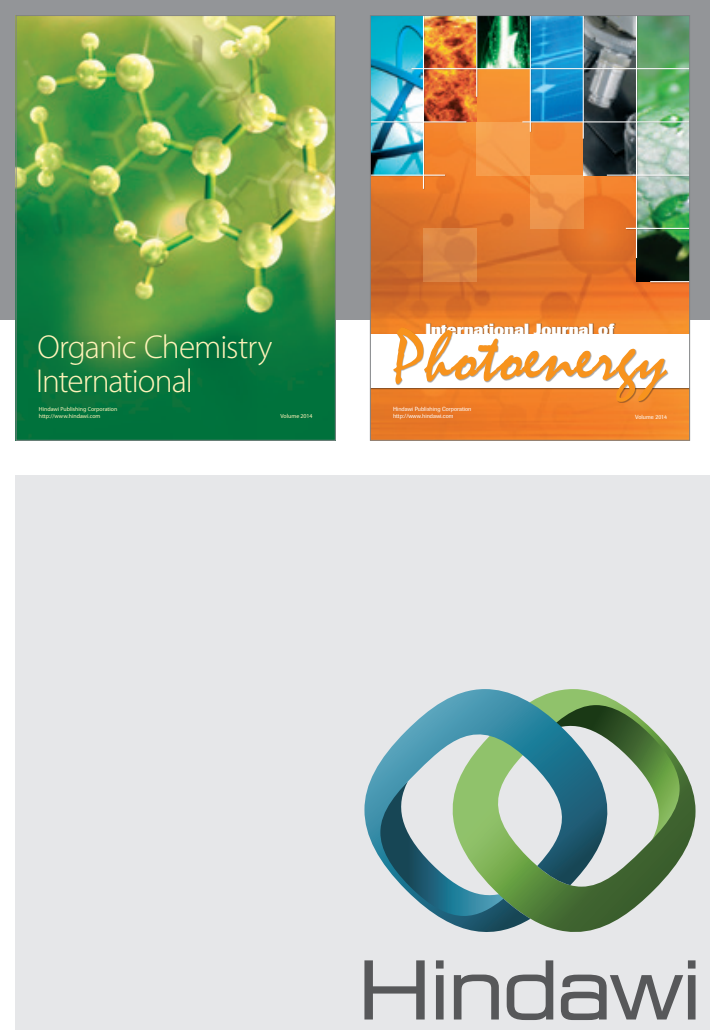

Submit your manuscripts at

http://www.hindawi.com
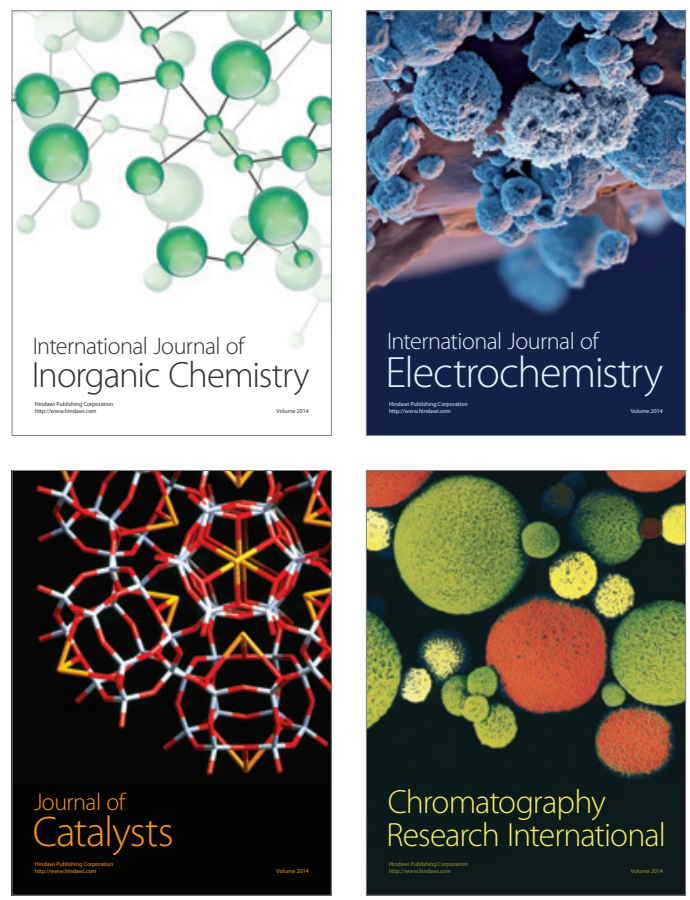
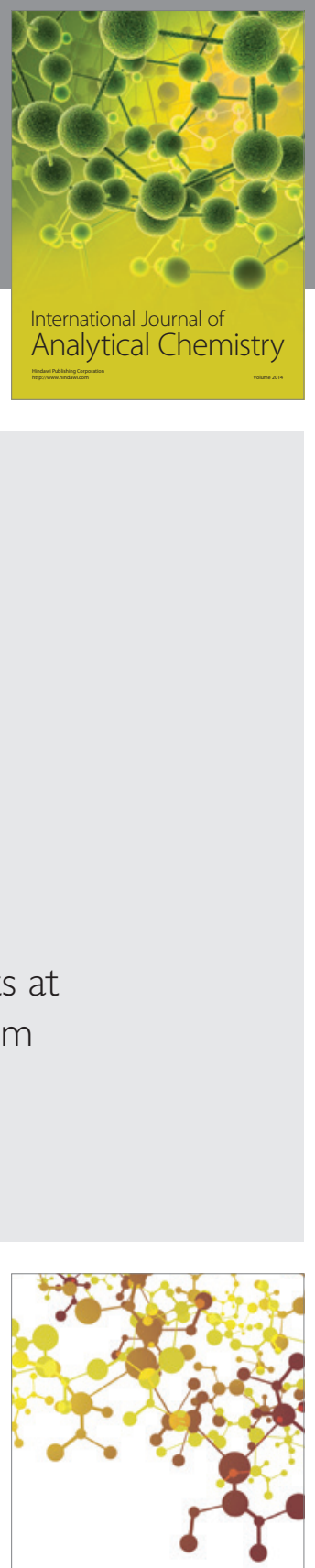

Journal of

Applied Chemistry
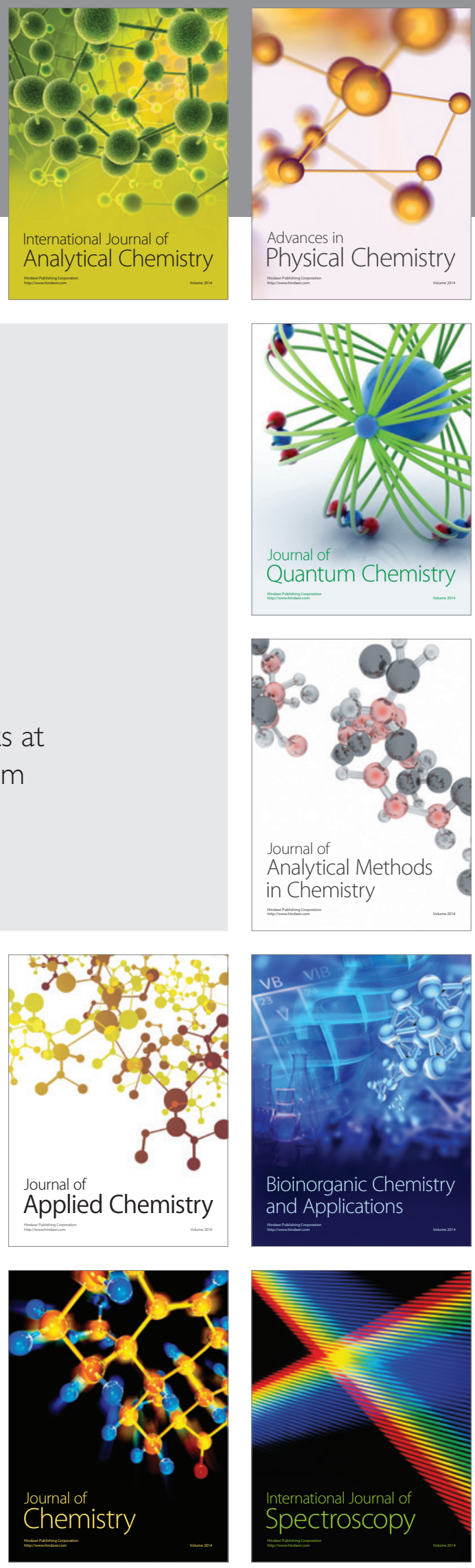